\title{
METHOXYCARBONYLATION OF STYRENE BY PALLADIUM(II) COMPLEX CONTAINING THE DIPHENYLPHOSPHINOCYRHETRENE LIGAND
}

\author{
CÉSAR ZÚNIIGA, DIEGO SIERRA, JUAN OYARZO Y A. HUGO KLAHN* \\ Pontificia Universidad Católica de Valparaíso, Campus Curauma, Avda. Universidad 330, Valparaíso, Chile. \\ (Received: July 31, 2011 - Accepted: March 16, 2012)
}

\begin{abstract}
The palladium-catalyzed methoxycarbonylation of vinylarenes has been investigated for the first time using phosphinocyrhetrene $\left[\left(\eta^{5}-\mathrm{C}_{5} \mathrm{H}_{4} \mathrm{PPh}{ }_{2}\right) \mathrm{Re}(\mathrm{CO})_{3}\right]$ a non-metallocenic organometallic ligand. The catalytic system trans $-\left[\left(\eta^{5}-\mathrm{C}_{5} \mathrm{H}_{4} \mathrm{PPh}_{2}\right) \mathrm{Re}(\mathrm{CO})_{3}\right] \mathrm{PdCl}_{2}(\mathrm{NCMe}) / \mathrm{PPh}_{3}(1: 2$ ratio), carbon monoxide and methanol, in the presence of $\mathrm{HCl}$ as acidic promoter, showed good catalytic activity, excellent regioselectivity to the branched products and chemoselectivity up to $94 \%$.
\end{abstract}

Keywords: Methoxycarbonylation, phosphinocyrhetrene ligand, vinylarenes.

\section{1.- INTRODUCTION}

Palladium-catalyzed hydroesterification reaction (Reppe carbonylation) is a powerful synthetic strategy for the preparation of linear and branched esters from easily available unsaturated substrates. ${ }^{1,2}$ It has been established that the regioselectivity of carboxylation products is strongly dependent on the ligands bound to a transition metal and the reaction conditions. The most common catalytic system involve Pd(II) and mono- and bidentate aromatic phosphines. Catalysts containing bidentate diphosphine ligands have been more frequently used for this reaction, but they have the disadvantage to produce branched product in low regio- and enantioselectivity, although a few successful examples have been reported recently. ${ }^{3-7}$ Several chelating diphosphines have been extensively studied, particularly interesting are those containing metallocenic fragments, for instance, palladium(II) complexes with 1,1-bis(diphenylphosphino)ferrocene (dppf), 1,1-bis(diphenylphosphino) octamethylferrocene (dppomf), 1,1-bis(diphenyl-phosphino)ruthenocene (dppr), and bis(diphenylphosphino)osmocene (dppo) have proven to catalyze the methoxycarbonylation of ethylene and styrene, showing high selectivity to the linear ester. ${ }^{8-13}$ Gusev et. al. ${ }^{14}$ have stated that the steric and electronic properties of these metallocenes carrying phosphine ligands, should form $\mathrm{M}-\mathrm{Pd}(\mathrm{M}=\mathrm{Fe}, \mathrm{Ru}$ and $\mathrm{Os})$ bonds throughout the catalytic cycle, favoring the formation of the linear product. Recently, it has been established, that products with high linearity can be achieved by using chelating systems, in which the diphosphines promote the most favored cis-coordinated complexes. ${ }^{15}$

On the other hand, palladium complexes containing monodentate phosphine ligands have also been of interest for the catalyzed-hydroesterification reactions since their use provides high regioselectivity to the branched ester but the enantioselectivity is usually low. Despite the large number of monophosphine containing ferrocene described in literature ${ }^{16}$ only few of them have been used in hydroesterification reactions. This situation contrast with the remarkably success of ferrocenyl phosphines for palladium catalyzed C-C, C-N and C-O bond-forming cross coupling. ${ }^{17-19}$ Recently, Claver et al. have demonstrated that ferrocenylphosphoetane ligand produces high regioselectivity (99:1, b:l) but low conversion. ${ }^{20}$

According to our acknowledge, no others cyclopentadienylphosphines ${ }^{21}$ containing metals have been used as ligands in Pd-catalyzed hydroxycarbonylation reactions and considering that recently we have published the synthesis, characterization and catalytic evaluation on Suzuki cross-coupling reactions, of a series of bimetallics complexes containing the metalloligands $\left(\eta^{5}-\mathrm{C}_{5} \mathrm{H}_{4} \mathrm{PPh}_{2}\right) \operatorname{Re}(\mathrm{CO})_{2}(\mathrm{~L}) \mathrm{L}=\mathrm{CO}, \mathrm{PMe}_{3}$ and $\mathrm{P}(\mathrm{OMe})_{3},{ }^{22,23}$, 24 in this paper, we report the results obtained on the methoxycarbonylation of olefins catalyzed by the bimetallic complex trans- $\left[\left(\eta^{5}-\mathrm{C}_{5} \mathrm{H}_{4} \mathrm{PPh}_{2}\right) \mathrm{Re}(\mathrm{CO})_{3}\right]$ $\mathrm{PdCl}_{2}(\mathrm{NCMe})$ (Figure 1). The effect of various reaction parameters such as, acidic promoters, $\mathrm{CO}$ pressure and auxiliary ligand to metal ratio, have been evaluated on the outcome of the reaction.

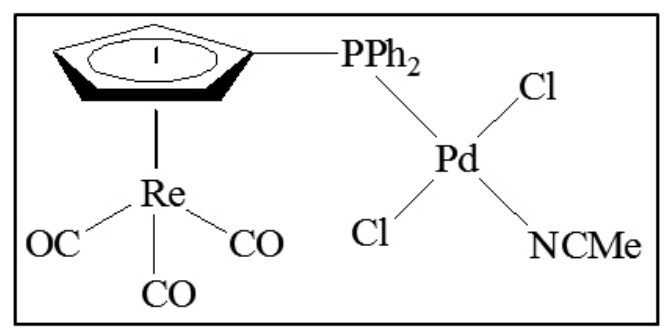

Figure 1. Complex trans- $\left[\left(\eta^{5}-\mathrm{C}_{5} \mathrm{H}_{4} \mathrm{PPh}_{2}\right) \mathrm{Re}(\mathrm{CO})_{3}\right] \mathrm{PdCl}_{2}(\mathrm{NCMe})$ used in methoxycarbonylation of vinylarenes.

\section{2.- EXPERIMENTAL SECTION}

All experiments were performed under nitrogen using standard Schlenck techniques. Organic solvents were purified by standard methods. All chemicals were reagent-grade and used as received unless otherwise specified styrene, $p-\mathrm{CH}_{3} \mathrm{C}_{6} \mathrm{H}_{4} \mathrm{SO}_{3} \mathrm{H} \cdot \mathrm{H}_{2} \mathrm{O}(p-\mathrm{TsOH})$, hydrochloric acid and $\mathrm{PPh}_{3}$ were purchased from Aldrich. The trans- $\left[\left(\eta^{5}-\mathrm{C}_{5} \mathrm{H}_{4} \mathrm{PPh}_{2}\right) \mathrm{Re}(\mathrm{CO})_{3}\right] \mathrm{PdCl}_{2}(\mathrm{NCMe})$ complex was prepared according to method reported by our laboratory. ${ }^{22} \mathrm{GC}$ analyses were performed on an Agilent Technlogies 6890N chromatographer with a flame ionization detector (FID) equipped with a $30 \mathrm{~m} \times 320 \mu \mathrm{m} \times 0.25 \mu \mathrm{m}$ HP-5 column.

The catalytic methoxycarbonylation reactions were carried out in a glasslined stainless steel autoclave fitted with a temperature control unit and a sampling valve. In the reactor, previously evacuated by a vacuum pump, were added the pre-catalyst $(0.00735 \mathrm{mmol}), p$-TsOH acid or hydrochloric acid $(0.0735 \mathrm{mmol}), \mathrm{PPh}_{3}(0.015 \mathrm{mmol})$, and methanol $(20 \mathrm{~mL})$. The reactor was then charged to the required pressure at room temperature and heated at $75^{\circ} \mathrm{C}$.

\section{3.- RESULTS AND DISCUSSION}

3.1.- Methoxycarbonylation of styrene using $\left[\left(\eta^{5}-\mathrm{C}_{5} \mathrm{H}_{4} \mathrm{PPh}_{2}\right) \mathrm{Re}(\mathrm{CO})_{3}\right]$ $\mathrm{PdCl}_{2}(\mathrm{NCMe})$ : Screening of conditions catalysts.

Products of the hydroesterification reaction of styrene with $\mathrm{CO}$ and methanol obtained in this study are shown in Scheme 1. The major products were methyl-3-phenylpropanoate (linear product 1), methyl-2-phenylpropanoate (branched product 2) and (1- methoxyethyl)benzene (etherification product $\mathbf{3}$ ).

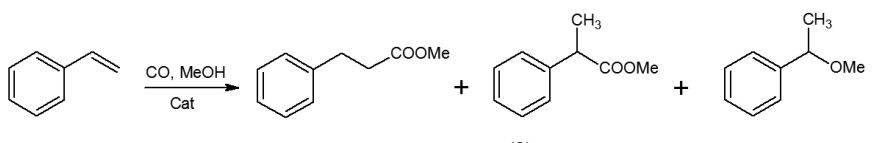

(1)

(2)

(3)

Scheme 1. Methoxycarbonylation of styrene.

The results of the methoxycarbonilation reaction of styrene with different catalytic systems are listed in Table 1. 
Table 1. Experimental data for the methoxycarbonylation of styrene.

\begin{tabular}{|c|c|c|c|c|c|}
\hline Entry & $P P h_{3}$ & CO [bar] & Conversion(\%) & b/l ratio (\%) & Chemoselectivity ester (\%) \\
\hline 1 & -- & 50 & traces & -- & 79 \\
\hline 2 & 2 & 50 & $14(1+2+3)$ & $63 / 37$ & 86 \\
\hline 3 & 2 & 50 & $20(1+2+3)^{\mathrm{a}}$ & $60 / 40$ & -- \\
\hline 4 & -- & 80 & Traces & - & 100 \\
\hline 5 & 2 & 80 & $19(1+2)$ & $74 / 26$ & 98 \\
\hline 6 & 4 & 80 & $25(1+2+3)$ & $70 / 30$ & 98 \\
\hline 7 & 6 & 80 & $58(1+2+3)$ & $44 / 56$ & 97 \\
\hline 8 & 2 & 80 & $97(1+2+3)^{\mathrm{b}}$ & $92 / 8$ & 94 \\
\hline 9 & -- & 80 & $79(1+2+3)^{\mathrm{b}}$ & $97 / 3$ & 99 \\
\hline 10 & 2 & 50 & $100(1+2+3)^{\mathrm{b}}$ & $91 / 9$ & 94 \\
\hline 11 & -- & 50 & $80(1+2+3)^{\mathrm{b}}$ & $98 / 2$ & 96 \\
\hline 12 & -- & 50 & $31(1+2+3)^{\mathrm{c}}$ & $82 / 18$ & 100 \\
\hline 13 & -- & 50 & $62(1+2)^{\mathrm{b}, \mathrm{c}}$ & $85 / 15$ & -- \\
\hline 14 & -- & 50 & $T^{\mathrm{braces}}{ }^{\mathrm{b}, \mathrm{d}}$ & -- & 97 \\
\hline
\end{tabular}

Reaction conditions: Solvent: methanol $20 \mathrm{~mL}$; Pd/Subs. ratio 1:100, $\mathrm{Pd} / p$-TsOH ratio 1:10; temperature: $75^{\circ} \mathrm{C}$; time $24 \mathrm{~h}$; b/1 branched ester/lineal ester ratio. (a) Time 48 h. (b) $\mathrm{Pd} / \mathrm{HCl}$ ratio 1:10. (c) Using $\mathrm{Pd}\left(\mathrm{PPh}_{3}\right)_{2} \mathrm{Cl}_{2}$ catalyst. (d) Using $\mathrm{Pd}\left(\mathrm{CH}_{3} \mathrm{CN}\right)_{2} \mathrm{Cl}_{2}$ catalyst.

The results shown in Table 1, indicate low conversions to products, under moderated conditions of pressure and temperature in the presence of $p$-toluensulfonic acid ( $p$-TsOH) (entries 1-7 and 12), however a significant improvement is achieved by adding $\mathrm{PPh}_{3}$ (auxiliary ligand) to the catalytic system but regioselectivities still remain low (entries 2,3,5-7). By considering the literature antecedents, ${ }^{3,25}$ we believe that the presence of $\mathrm{PPh}_{3}$ can help to stabilize the catalyst, by forming the bimetallic complex trans- $\left[\left(\eta^{5}-\mathrm{C}_{5} \mathrm{H}_{4} \mathrm{PPh}_{2}\right)\right.$ $\left.\operatorname{Re}(\mathrm{CO})_{3}\right]\left(\mathrm{PPh}_{3}\right) \mathrm{PdCl}_{2}$ which avoid the formation of $\mathrm{Pd}(0)$ species, even thought small amount of palladium black was always observed in these reactions.

Increasing the amount of triphenylphosphine increase the conversion but a noticeably decrease on the regioselectivity is observed (entries 5-7), probably the excess of $\mathrm{PPh}_{3}$ displace the metalloligand forming $\mathrm{Pd}\left(\mathrm{PPh}_{3}\right)_{2} \mathrm{Cl}_{2}$ as the catalytic specie, which is known to catalyze the metoxycarbonylation of styrene in moderate conversion and regioselectivity ${ }^{13}$ (entry 12-13). To prove the above assumption we evaluate the catalytic properties of $\mathrm{Pd}\left(\mathrm{PPh}_{3}\right)_{2} \mathrm{Cl}_{2}$ under the same experimental conditions (entry 12). In view of these results, the optimized ratio catalyst/auxiliary ligand was 1:2.

In most of the cases, the chemoselectivities were quite high but the formation of the ether (3) increase under longer reaction time (entry 3). It is noteworthy that etherification products are normally formed by acid-catalyzed addition of methanol to styrene. ${ }^{26}$ Similar results have been previously reported for other catalytic systems of $\mathrm{Pd}(\mathrm{II}) /$ phosphines/ $p$-TsOH. ${ }^{27,}{ }^{28} \mathrm{In}$ agreement with other Pd-catalytic systems containing monodentate phosphines, ${ }^{3-5,18}$ our system show favorable regioselectivity to form methyl-2-phenylpropanoate (Table 1).

A speculative explanation of these results can be given by considering the electron-withdrawing properties of cyrhetrenyl fragment which decrease the basicity on the phosphorous atom and therefore, forming an electron-poor catalyst which might lead to an (alkoxycarbonyl)palladium species, which direct the insertion of the olefin to branched products. We have not ruled out that the steric factor of the metalloligand can also affect the regioselectivity.

The nature of the acidic promoter, is another important feature which deserve some comments, our experimental data (Table 1) show that the presence of 10 -fold excess of $p$-TsOH (entry 5 ), the conversion was measured to be $14 \%$ and 19\% (at CO pressure of 50 (entry 2) and 80 bar (entry 5)), respectively. In both cases, a moderated regioselectivity to the branched product was also observed (63\% and $74 \%$, respectively). When hydrochloric acid was used as acid promoter a remarkably increase was noted in the conversion, regio- and chemoselectivity (entries 10 and 8), at the two different $\mathrm{CO}$ pressure. These results are not surprising since Claver et. al. ${ }^{5,29}$ and Chaudhari et. al. ${ }^{28}$ have reported similar observation for the methoxycarbonylation of styrene by using other Pd-catalytic systems and $\mathrm{HCl}$ as the acid source. Accordingly, we also believe that the better coordinating capability of $\mathrm{Cl}^{-}$vs. $p$ - $\mathrm{TsO}^{-}$will favor the formation of neutral species [ $\mathrm{PdHCl}($ phosphine)(styrene)] which have been suggested to be an intermediate for the formation of branched esters. ${ }^{29}$

With the aim to probe the involvement of our bimetallic complex in the catalytic reaction, we compared its catalytic activity with the complexes $\mathrm{Pd}\left(\mathrm{PPh}_{3}\right)_{2} \mathrm{Cl}_{2}$ and $\mathrm{Pd}\left(\mathrm{CH}_{3} \mathrm{CN}\right)_{2} \mathrm{Cl}_{2}$ under identical experimental conditions. In terms of conversion, almost a $20 \%$ increase was noted when compared $\left[\left(\eta^{5}-\mathrm{C}_{5} \mathrm{H}_{4} \mathrm{PPh}_{2}\right) \mathrm{Re}(\mathrm{CO})_{3}\right] \mathrm{PdCl}_{2}(\mathrm{NCMe})$ (entry 11) vs. $\mathrm{Pd}\left(\mathrm{PPh}_{3}\right)_{2} \mathrm{Cl}_{2}$ (entry 13$)$. Furthermore, a notorious improvement was also found in the regioselectivity to the branched product.

A more dramatic differences were found with the complex $\mathrm{Pd}\left(\mathrm{CH}_{3} \mathrm{CN}\right)_{2} \mathrm{Cl}_{2}$ (entry 14) which under the experimental conditions used, is inactive. The different catalytic behavior of the $\mathrm{Pd}(\mathrm{II})$ center coordinated to diphosphinocyrhetrene ligand $\left(\eta^{5}-\mathrm{C}_{5} \mathrm{H}_{4} \mathrm{PPh}_{2}\right) \operatorname{Re}(\mathrm{CO})_{3}$ compared to $\mathrm{PPh}_{3}$ can be attributed to the steric and electronic properties induced by the cyrhetrenyl group bound to the phosphorous atom. Consequently, the catalytic performance of the palladium complexes bearing such ligands should be altered, as we observed.

\section{ACKNOWLEDGEMENTS}

The authors thank Fondecyt-Chile (Project N 3090035 and 1060487). We also acknowledge the Dirección de Investigación of Pontificia Universidad Católica de Valparaíso for financial support. D. S. acknowledges MECESUP and CONICYT for a Doctoral scholarship. We also thank to Professor Dr. Sergio A. Moya of Universidad de Santiago de Chile for allowing us the use of a Gas Chromatographer.

\section{REFERENCES}

1.- G. Kiss, Chem. Rev. 101, 3435, (2001)

2.- A. Brennfuhrer, H. Neumann, M. Beller, Chem. Cat. Chem. 1, 28, (2009)

3.- I. Del Río, N. Ruiz, C. Claver, L. A. van der Veen, P.W.N.M. van Leeuwen, J. Mol. Catal. A Chem. 161, 39, (2000).

4.- B. Muñoz, E. Santos Garcia, C. Godard, E. Zangrando, C. Bo, A. Ruiz, C. Claver, Eur. J. Inorg. Chem. 4625, (2008).

5.- B. K. Muñoz, C. Godard, A. Marinetti, A. Ruiz, J. Benet-Buchholz, C. Claver, Dalton Trans. 36, 5524, (2007).

6.- I. del Rio, C. Claver, P.W.N.M. van Leeuwen, Eur. J. Inorg. Chem. 2719, (2001).

7.- P.W.N.M. van Leeuwen, M.A. Zuideveld, B.H.G. Swennenhuis, Z. Freixa, P.C.J. Kamer, K. Goubitz, J. Fraanje, M. Lutz, A.L. Spek, J. Am. Chem. Soc. 125, 5523, (2003).

8.- C. Bianchini, A. Meli, W. Oberhauser, S. Parisel, O.V. Gusev, A.M. 
Kal'sin, N.V. Vologdin, F.M. Dolgushin, J. Mol. Catal. A Chem. 224, 35, (2004).

9.- B. Jedlicka, W. Weissensteiner, T. Kégl, L. Kollár, J. Organomet. Chem. 563, 37,(1998)

10.- C. Bianchini, A. Meli, W. Oberhauser, P.W.N.M. van Leeuwen, M.A. Zuideveld, Z. Freixa, P.C.J. Kamer, A.L. Spek, O.V. Gusev, A.M. Kal'sin, Organometallics 22, 2409, (2003)

11.- O.V. Gusev, A.M. Kal'sin, P.V. Petrovskii, K.A. Lyssenko, Y.F. Oprunenko, C. Bianchini, A. Meli, W. Oberhauser, Organometallics 22, 913, (2003).

12.- L. Diab, M. Gouygou, E. Manoury, P. Kalck, M. Urrutigoïty, Tetrahedron Lett. 49, 5186, (2008).

13.- C. Zúñiga, S.A. Moya, P. Aguirre, Catal. Lett. 130, 373, (2009).

14.- A.M. Kal'sin, N.V. Vologdin, T.A. Peganova, P.V. Petrovskii, K. A. Lyssenko, F.M. Dolgushin, O.V. Gusev, J. Organomet. Chem. 691, 921, (2006).

15.- E. Guiu, M. Caporali, B. Muñoz, C. Müller, M. Lutz, A.L. Spek, C. Claver, P.W.N.M. van Leeuwen, Organometallics 25, 3102, (2006)

16.- R. C. J. Atkinson, N. J. Long in Ferrocenes: Ligands, materials and biomolecules, P. Stepnicka Ed., John Wiley \& Sons, West Sussex, 2008, pp. 3-32.

17.- N. Kataoka, Q. Shelby, J. Stambuli, J. F. Hartwig, J. Org. Chem. 67, 5553, (2002).
18.- M.D. Sliger, G.A. Broker, S.T. Griffin, R.D. Rogers, K.H. Shaughnessy, J. Organomet. Chem. 690, 1478, (2005).

19.- S. Eichenseher, O. Delacroix, K. Kromm, F. Hampel, J.A. Gladysz, Organometallics 24, 245, (2005).

20.- B. Muñoz, A. Marinetti, A. Ruiz, S. Castillon, C. Claver, Inorg. Chem. Commun. 8, 1113, (2005).

21.- F. Godoy, A.H. Klahn, F. Lahoz, B. Oelckers, L.A. Oro, J. Chil. Chem. Soc. 49, 231,(2004).

22.- D. Sierra, A. Muñoz, F. Godoy, A.H. Klahn, A. Ibáñez, M.T. Garland, M. Fuentealba Polyhedron 28, 322, (2009).

23.- D. Sierra, F. Godoy, A.H. Klahn, R. Ramirez, R. Arratia, M. Fuentealba, M.T. Garland Dalton Trans. 39, 6295, (2010).

24.- D. Sierra, C. Zuñiga, G. E. Buono-Core, F. Godoy, A. H. Klahn, Inorg. Chem. Commun. 14, 961, (2011)

25.- A. Seayad, A.A. Kelkar, L. Toniolo, R.V. Chaudhari, J. Mol. Catal. 151, $47,(2000)$.

26.- M. B. Smith, J. March, Advanced Organic Chemistry: Reactions, Mechanisms and Structures, 5th edn, Wiley-VCH, Weinheim, 2001.

27.- J. Gironès, J. Duran, A. Polo, J. Real, J. Mol. Catal. A Chem. 198, 77, (2003).

28.- S.B. Atla, A.A. Kelkar, R.V, Chaudhari, J. Mol, Catal. A Chem. 307, 134 , (2009).

29.- I. del Rio, N. Ruiz, C. Claver, Inorg. Chem. Commun. 3, 166, (2000). 